Pilar Ferré, Manuel Anglada-Tort, Marc Guasch

\title{
Processing of emotional words in bilinguals: Testing the effects of word concreteness, task type and language status
}

Journal article | Accepted manuscript (Postprint)

This version is available at https://doi.org/10.14279/depositonce-9111

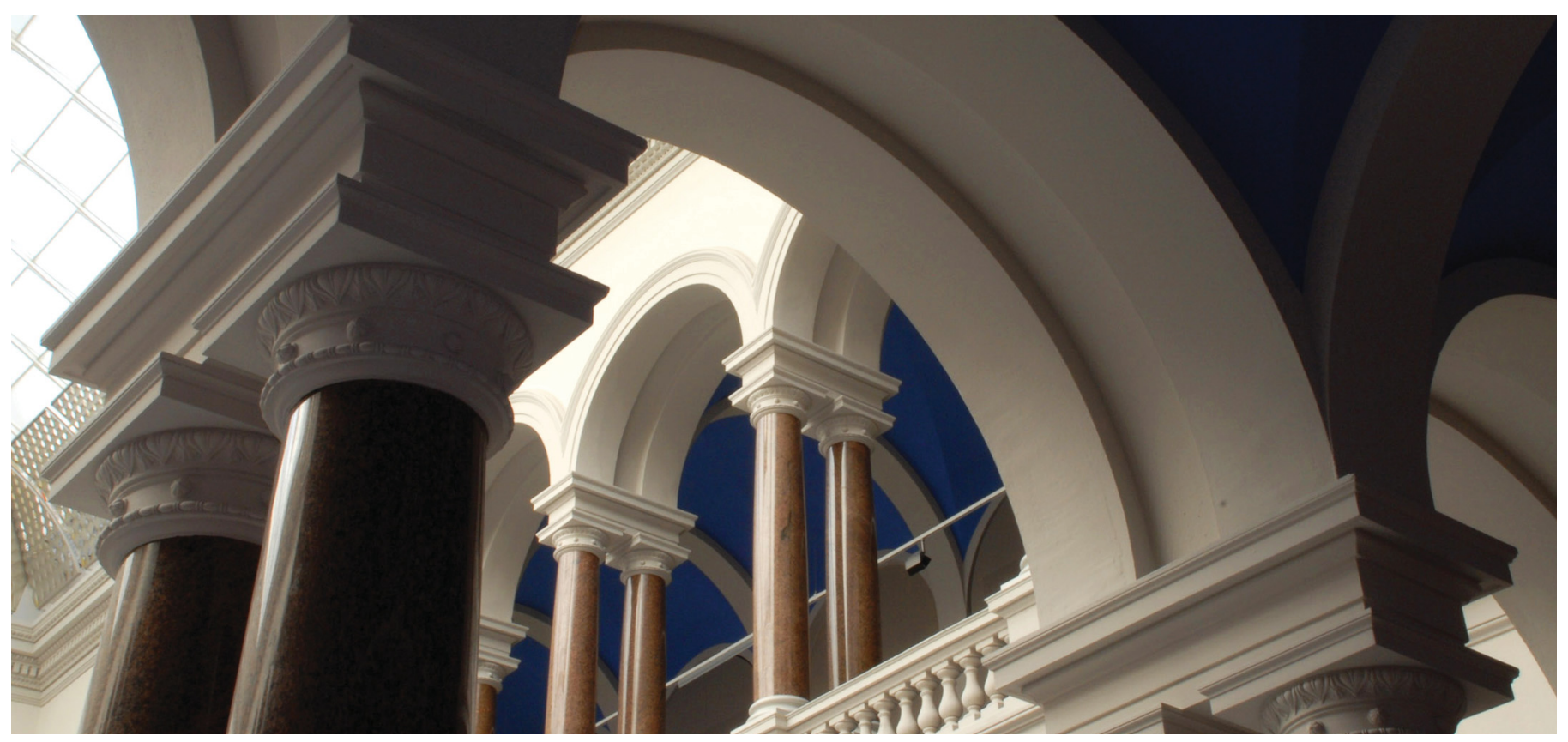

Ferré, P.; Anglada-Tort, M.; Guasch, M.: Processing of emotional words in bilinguals: Testing the effects of word concreteness, task type and language status. Second Language Research 34 (3) pp. 371-294. Copyright @ SAGE. DOI: https://doi.org/10.1177/0267658317744008 


\section{Note}

This is an accepted manuscript (post-print version) of an article published in Second Language Research, available online at

http://journals.sagepub.com/doi/full/10.1177/0267658317744008

TITLE

Processing of emotional words in bilinguals: Testing the effects of word concreteness, task type and language status.

\section{AUTHORS}

Pilar Ferré ${ }^{1}$, Manuel Anglada-Tort ${ }^{2}$, and Marc Guasch ${ }^{1}$

${ }^{1}$ Department of Psychology and CRAMC, Universitat Rovira i Virgili, Tarragona, Spain.

${ }^{2}$ Audio Communication Department, Technische Universität Berlin, Germany.

\section{CORRESPONDING AUTHOR:}

Pilar Ferré

Department of Psychology and CRAMC. Universitat Rovira i Virgili

Crta. de Valls s/n., 43007. Tarragona. Spain

E-mail: mariadelpilar.ferre@urv.cat

Telephone Number: +34-977-257896

FUNDING: This work was supported by the Ministerio de Economía y Competitividad of Spain and the Fondo Europeo de Desarrollo Regional (MINECO/FEDER) (Grants Nos. PSI2015-63525-P, PCIN-2015-165-C02-02), as well as Ref. 2016PFR-URV-B2-37 from the Universitat Rovira i Virgili. 


\section{ABSTRACT}

The present study investigates whether the emotional content of words has the same effect in the different languages of bilinguals by testing the effects of word concreteness, the type of task used, and language status. Highly proficient bilinguals of Catalan and Spanish, who learned Catalan and Spanish in early childhood in a bilingual immersion context and who still live in such a context, performed an affective decision task (Experiment 1) and a lexical decision task (Experiment 2) in both Catalan and Spanish. A different set of Catalan-Spanish bilinguals, who were proficient in English and who learned English after early childhood in an instructional setting, performed a lexical decision task in both Spanish and English (Experiment 3). In both tasks administered throughout the experiments, the experimental stimuli were concrete and abstract words that varied in their emotional connotation (i.e., positive, negative and neutral words) and were presented in the two languages involved. In the affective decision task, participants decided if the words had emotional content or not, and in the lexical decision task they decided if the strings of letters were real words or not. The three experiments also included an unexpected free recall task. Results showed that the emotional content of words affected bilinguals' performance in all three tasks. In particular, there was a disadvantage in processing for negative words in both the affective and lexical decision tasks, and an advantage for positive words in the lexical decision and free recall tasks. Importantly, language only interacted with the other variables in Experiment 3, suggesting that language status is a relevant factor in determining the extent to which emotional processing has the same characteristics in the two languages. 
Keywords: Emotional words, concreteness, bilingualism, lexical decision, affective decision. 
The emotional content of words plays a significant role in language processing. A number of studies have demonstrated that emotional words (i.e., words with an affective content, like love or death) are processed differently than neutral words (e.g., document, e.g., Estes \& Verges, 2008; Ferré, Fraga, Comesaña, \& Sánchez-Casas, 2015; Kensinger \& Corkin, 2003; Kissler \& Herbert, 2013; Kousta, Vinson, \& Vigliocco, 2009). The majority of work on emotional words has been conducted either with monolingual participants or in the native language of multilingual speakers. Nevertheless, interest in the processing of emotional words in non-native languages has grown over the last decade (see Pavlenko, 2008, 2012, and Caldwell-Harris, 2014, for reviews). The main question here is to determine whether the processing of emotional words has the same characteristics in the native language as in the non-native language of bilinguals. Research to date shows no clear-cut answers (see Pavlenko, 2012, for a review). Indeed, while some studies have found differences between the native and the non-native language in emotional word processing (Anooshian \& Hertel, 1994; Caldwell-Harris \& Ayçiçeği-Dinn, 2009; Caldwell-Harris, Tong, Lung, \& Poo, 2011; Chen, Lin, Chen, Lu, \& Guo, 2015; Degner, Doycheva, \& Wentura, 2012; Eilola \& Havelka, 2011; Harris, Ayçiçegi, \& Gleason, 2003; Opitz \& Degner, 2012; Winskel, 2013), other studies have shown that emotional words are similarly processed in both languages (Altarriba \& Basnight-Brown, 2010; Eilola, Havelka, \& Sharma, 2007; Ponari et al., 2015; Ferré, García, Fraga, Sánchez-Casas, \& Molero, 2010; Ferré, Sánchez-Casas, \& Fraga, 2013).

These divergences are due in part to a number of factors that modulate the effects of the emotional content of words. For instance, the particular characteristics of bilinguals, such as age of acquisition of the non-native language (Caldwell-Harris \& 
Ayçiçeği-Dinn, 2009; Chen et al., 2015; Colbeck \& Bowers, 2012; Harris et al., 2003), proficiency and use (e.g., Degner et al., 2012; Winskel, 2013) seem to be relevant. The effects of these variables can be understood through the "emotional contexts of learning hypothesis" (Harris, Gleason, \& Ayçiçegi, 2006), which considers that the context in which languages are learned and used is an important factor here. Hence, languages acquired in childhood have strong emotional resonances because they have been learned in a context that is rich in emotional experiences. A similar position is held by Pavlenko (2012), who considers that the native language is embodied because during its acquisition (i.e., during early childhood) there is an integration of the phonological forms of words with sensory-motor and emotional information (i.e., visual, auditory, olfactory and motor experiences, as well as emotional ones). By contrast, non-native languages are "disembodied", as they are typically learned in formal contexts, which are relatively devoid of emotionality and do not provide many opportunities for the integration of the foreign words with sensory-motor and emotional experiences (see also Jończyk, 2016).

Notably, not all the available evidence supports the "emotional contexts of learning hypothesis". For instance, Eilola et al. (2007) found that the interference produced by the emotional content of words, when a group of late bilinguals were asked to name the colors in which words were printed (i.e., the so-called emotional Stroop effect; Williams, Mathews, \& MacLeod, 1996), had the same magnitude in the native and the non-native language (see, however, Winskel, 2013 for evidence of an emotional Stroop effect restricted to the native language). On the same lines, emotional words were better remembered than neutral words in both languages of proficient bilinguals in the study of Ferré et al. (2010), an effect that was not affected by age of acquisition, context of acquisition or language proximity. Similarly, Ponari et al. (2015) 
demonstrated that the emotional effect in a lexical decision task (LDT) conducted in a non-native language (English) was not modulated by variables related to the bilinguals tested (age of acquisition, duration of stay in an English speaking country, frequency of usage, and similarity between the native language and English).

The studies outlined above, then, do not allow us to draw solid conclusions regarding the effects of emotional content on word processing in the different languages of multilingual speakers and the modulatory role of speaker related variables. It may be that some methodological factors not considered in previous research have contributed to these inconsistencies. The present work aims to shed more light on this issue by investigating the effects of the type of task, the characteristics of the words, and language status in the processing of emotional words in bilingual speakers.

As seen in the literature reviewed above, a diversity of tasks have been used in research. However, few studies have employed more than one task using the same experimental materials. For instance, Winskel (2013) asked a group of Thai-English bilinguals to provide emotionality ratings of Thai and English words after performing a bilingual emotional Stroop task. It was found that while there were no differences between the two languages in emotionality ratings, the emotional Stroop effect appeared only in the native language (Thai). Winskel argued that in the emotionality rating task, words are processed at a conscious and deep level. Therefore, because bilinguals know the meanings of non-native emotional words, it is logical that there are no differences between the two languages. Conversely, the effect of the emotional content of words in the emotional Stroop task reveals automatic and early lexical processing. Bearing in mind that some previous reports of similar processing of emotional stimuli in the native and the non-native language were obtained mainly with tasks focused on emotionality (e.g., Caldwell-Harris et al., 2011), these findings may have been the consequence of 
instructions directing the participants to the connotative meaning of words. Taking these findings into account, the present study aims to compare the emotional processing of words in the two languages in two different tasks, requiring bilinguals to focus either on the emotional content of words (affective decision task) or on non-emotional properties (LDT).

Apart from comparing different tasks, we also aimed to explore the role of the specific characteristics of emotional words on their processing in both languages. In particular, we focused on valence (i.e., positive vs. negative words) and concreteness. The inclusion of positive and negative words in the same study is relevant in light of recent findings suggesting that bilinguals process positive words similarly in the native and the non-native language while the processing of negative words is modulated by language (Conrad, Recio, \& Jacobs, 2011; Sheikh \& Titone, 2016; Wu \& Thierry, 2012). Indeed, while positive words showed event-related potential (ERP) modulations in both languages (Conrad et al., 2011), these modulations were observed for negative words only in the native language, not for their counterparts in the non-native language. In a related vein positive words in the non-native language, but not negative ones, were processed faster than neutral words as measured by eye-tracking recording during natural reading (Sheikh \& Titone, 2016). These findings have lead several authors to suggest that only the negative words of the non-native language would be disembodied.

From the perspective of embodiment, another distinction that should be considered is that between concrete and abstract words. Indeed, Kousta, Vigliocco, Vinson, Andrews, and Del Campo (2011) proposed an embodied theoretical view of semantic representation according to which sensory-motor information would be central to the representation and processing of concrete words, whereas affective information would be more relevant in the representation of abstract words. Concerning concrete 
words, their grounding in sensory-motor information would be the result of language being learned and used in interactive and real-world contexts. As noted above, this should be more prominent in the native language than in the non-native language, the latter usually learned in artificial environments (Foroni, 2015; Jończyk, 2016). With this in mind, the study reported here manipulated word concreteness to assess whether there is any modulation by language of the typical concreteness advantage found in monolingual studies (e.g., Binder, Westbury, Mckiernan, Possing, \& Medler, 2005). Moreover, we orthogonally manipulated concreteness and emotionality to assess whether language modulates a possible interaction between both factors. If emotional content is more important in the meaning and processing of abstract words than concrete words (Kousta et al., 2011), one would expect the processing of the former to be modulated to a greater extent by emotionality than the processing of the latter. Some studies conducted in native languages have supported such a proposal (e.g., Newcombe, Campbell, Siakaluk, \& Pexman, 2012; Zhao \& Wang, 2014). However, this might not occur in a non-native language if words here are emotionally disembodied.

To sum up, the aim of this study was to investigate whether the emotional content of words has the same effect in the different languages of bilinguals, by testing the effects of the characteristics of the words, the type of task and language status. We conducted three experiments. In two of these (Experiments 1 and 2) bilinguals of Catalan and Spanish performed the experiment in both languages. These participants were highly proficient bilinguals who learned Catalan and Spanish during early childhood, and who where immersed in both languages. Hence, both Catalan and Spanish could be considered as native languages for this population. In addition, as these participants used Catalan more frequently than Spanish and indeed prefered it, they could be considered as Catalan dominants. In the third experiment, Catalan- 
Spanish bilinguals who were also highly proficient in English, carried out the task in Spanish and English. These participants had learned English after early childhood in a classroom setting and lived in an environment of Spanish-Catalan immersion.The same experimental stimuli were used across experiments, namely concrete and abstract words that varied in their emotional connotation (i.e., positive, negative, and neutral words) presented in the two languages involved. In Experiment 1, Catalan-Spanish participants performed an affective decision task, and in Experiment 2 they did an LDT. Both tasks involved Catalan and Spanish words. In Experiment 3, an LDT was performed in Spanish and English. In addition, all three experiments included an unexpected free recall task. Considering the proposal of the "emotional contexts of learning hypothesis" (Harris et al., 2006), and taking into account that these bilinguals learned Catalan and Spanish during early childhood while being immersed in a bilingual environment, we hypothesized that language would not modulate the emotionality effect in tasks involving Catalan and Spanish. However, bearing in mind that these bilinguals have typically used Catalan more than Spanish through their life, there has been a higher probability for Catalan words to be associated with emotional situations than Spanish words. Thus, differences in emotionality might be observed between both languages, although they could be restricted to tasks that tap into automatic processing, as suggested by some other authors (Segalowitz, Trofimovich, Gatbonton, \& Sokolovskaya, 2008; Winskel, 2013). On these lines, we would expect the emotionality effect to interact with language in the LDT (Experiment 2), but not in tasks either focused on emotionality (affective decision task, Experiment 1) or involving more elaborate processing (free recall task in Experiments 1 and 2). Additionally, we expected a clear modulation of the emotionality effects by language in Experiment 3, in which Spanish and English were used. This is because English was acquired later than 
Catalan and Spanish, and was learned in an instructional setting. Furthermore, in the case of differences in emotional processing between the two languages involved in the experiments, these should be observed mainly for negative words, but not for their positive counterparts, as only the former seem to be disembodied. Ultimately, concerning the concreteness/abstractness dimension, if the disembodiment in the nonnative language affects both sensory-motor and emotional grounding, it might be that the advantage for concrete words in processing and the modulation of abstract word processing by emotionality is attenuated in the non-native language.

\section{EXPERIMENT 1}

\section{Method}

Participants. A sample of 39 participants (38 females), aged 17-32 ( $M=19.79$, $S D=3.21$ ), took part in the study. Participants were undergraduate students at the University Rovira i Virgili (Tarragona, Spain) who participated in the experiment in exchange for academic credits. They were Catalan-Spanish bilinguals. All the participants signed an informed consent form before starting the experiment. To assess their proficiency in Catalan and Spanish, they completed a questionnaire in which they rated their ability in reading, writing, speaking, and listening on a 7-point Likert scale (1 $=$ 'very poor level'; 7 = 'very good level'). They were also asked for the age of exposure to each language, as well as for language preference and use. All participants were exposed to Catalan from birth, and their average age of exposition to Spanish was 2.46 years $(\mathrm{SD}=2.20)$. Hence, they were all highly proficient in both languages (see Table 1). However, a paired comparison between Catalan $(M=6.94, S D=0.18)$ and Spanish $(M=6.65, S D=0.44)$ revealed an advantage for Catalan in average reported proficiency, $t(38)=4.47, p<.001$. The questionnaire also showed that Catalan was the 
language preferred in most cases and was also the more frequently used by these participants overall. Thus, participants were early sequential bilinguals of Catalan and Spanish, being highly proficient in both languages, but considering themselves as Catalan dominants.

Table 1. Mean and standard deviation (in parentheses) of participants' self-rated proficiency in the three languages

Experiment $1 \quad$ Experiment $2 \quad$ Experiment 3

Catalan proficiency

\begin{tabular}{llll}
\hline Read & $6.92(0.27)$ & $7.00(0.00)$ & $6.82(0.65)$ \\
Write & $6.87(0.34)$ & $6.98(0.16)$ & $6.69(1.03)$ \\
Speak & $6.95(0.22)$ & $6.98(0.16)$ & $6.69(0.95)$ \\
Listen & $7.00(0.00)$ & $7.00(0.00)$ & $6.94(0.24)$ \\
Spanish proficiency & & & \\
\hline Read & $6.62(0.71)$ & $6.65(0.58)$ & $6.88(0.38)$ \\
Write & $6.72(0.51)$ & $6.70(0.61)$ & $6.75(0.48)$ \\
Speak & $6.31(0.86)$ & $6.40(0.90)$ & $6.55(0.76)$ \\
Listen & $6.97(0.16)$ & $6.80(0.46)$ & $6.86(0.45)$
\end{tabular}

English proficiency

\begin{tabular}{lccc}
\hline Read & - & - & $5.37(0.69)$ \\
Write & - & - & $4.96(0.92)$ \\
Speak & - & - & $4.94(0.99)$ \\
Listen & - & - & $5.18(0.82)$ \\
\hline
\end{tabular}


Design and materials. The study employed a 2x3x2 design. The factors involved were Language (words presented in Catalan vs. Spanish), emotionality (positive, negative, and neutral words) and concreteness (concrete vs. abstract words).

A set of 144 Spanish words and their Catalan translations were selected (see Appendix). Table 2 shows the affective, semantic and lexical characteristics of the stimuli. The Spanish words were taken from the database of Guasch, Ferré, and Fraga (2015). These words had been rated on two 9-point scales in terms of valence $(1=$ 'very negative'; $9=$ 'very positive' $)$ and arousal $(1=$ 'non-arousing at all'; $9=$ 'very arousing'). For the variable of emotionality, we selected positive (e.g., kiss), negative (e.g., death), and neutral (e.g., chair) words. We also divided the stimulus set into concrete (e.g., ambulance) and abstract (e.g., freedom) words. Concreteness Values for concreteness were obtained from Duchon, Perea, Sebastián-Gallés, Martí, and Carreiras (2013), and from Guasch et al. (2015), studies in which words had been rated on a 7point scale $(1=$ 'very abstract; 7 = 'very concrete'). Word imageability and context availability were also taken into account. Imageability values were obtained from the same sources as concreteness, and context availability from Guasch et al. (2015). Frequency values of the Spanish words were drawn from Duchon et al. (2013). Furthermore, the frequency values of the Catalan translations of Spanish words, as well as the degree of orthographic similarity (OS, $0=$ 'not similar at all'; $1=$ 'identical') between translation pairs, were obtained through the online tool NIM (Guasch, Boada, Ferré, \& Sánchez-Casas, 2013). We divided the experimental stimuli into two sets, A and $\mathrm{B}$. The order of presentation of the two experimental sets, as well as the language of presentation for each set, were fully counterbalanced. Thus, 4 experimental files were created. Finally, we selected an additional pool of 48 neutral, filler words in order to ensure that half of the stimuli in the affective decision task required a 'yes' response and 
the other half required a 'no' response. The final set of stimuli, then, consisted of 192 words: 96 emotional words (48 positive words and 48 negative words, all of them critical words) and 96 neutral words (48 critical words and 48 filler words).

Table 2. Affective, semantic, and lexical characteristics of the stimuli

\begin{tabular}{|c|c|c|c|c|c|c|}
\hline \multirow[b]{3}{*}{ Affective and Semantic properties } & \multicolumn{3}{|c|}{ Concrete } & \multicolumn{3}{|c|}{ Abstract } \\
\hline & Positive & Negative & Neutral & Positive & Negative & Neutral \\
\hline & & & & & & \\
\hline \multicolumn{7}{|c|}{ (values from Spanish databases) } \\
\hline Valence & 6.91 & 2.40 & 4.89 & 7.38 & 2.31 & 4.80 \\
\hline Arousal & 6.11 & 7.11 & 3.81 & 6.51 & 6.95 & 4.23 \\
\hline Concreteness & 5.78 & 5.72 & 5.67 & 3.58 & 3.67 & 3.54 \\
\hline Imageability & 5.76 & 5.60 & 5.68 & 3.93 & 3.89 & 3.61 \\
\hline Context availability & 5.78 & 5.41 & 5.38 & 4.74 & 4.35 & 4.20 \\
\hline \multicolumn{7}{|l|}{ Lexical characteristics } \\
\hline Orthographic similarity & 0.65 & 0.64 & 0.64 & 0.63 & 0.62 & 0.63 \\
\hline Spanish word frequency & 21.48 & 14.60 & 34.36 & 24.02 & 14.61 & 26.95 \\
\hline Catalan word frequency & 17.28 & 14.09 & 19.62 & 19.86 & 14.07 & 17.62 \\
\hline Spanish number of letters & 7.42 & 7.29 & 7.79 & 7.88 & 7.54 & 7.38 \\
\hline Catalan number of letters & 6.75 & 7.08 & 6.54 & 7.63 & 7.13 & 6.54 \\
\hline
\end{tabular}

A 2x3 factorial ANOVA with concreteness (concrete and abstract words) and emotionality (positive, negative, and neutral words) as between-group factors was used to check that conditions differed only in the manipulated variables. This analysis showed that concrete and abstract words were significantly different in concreteness 
$F(1,138)=822.84, p<.001$; context availability $F(1,138)=64.79, p<.001$, and imageability $F(1,138)=192.38, p<.001$. In addition, positive, negative, and neutral words were significantly different in valence $F(2,138)=715.56, p<.001$, and in arousal $F(2,138)=237.12, p<.001$. No other variable revealed statistical differences among conditions (all $p$-values $>.10$ ). Additionally, as the experimental stimuli were divided into two sets, we ran independent-samples $t$ tests to ensure that there were no differences between both sets in terms of any variable. None of the tests revealed significant differences (all $p$-values $>.13$ ). Finally, the 48 filler neutral words were matched to the critical words for frequency, length, orthographic similarity, concreteness, and imageability (all $p$-values $>.34$ ).

Procedure. Participants were randomly assigned to one of the four experimental files created for the purpose of counterbalance. They were individually tested in separate soundproof booths. Each trial began with a fixation cross in the centre of the screen for $400 \mathrm{~ms}$, followed by the presentation of each stimulus for $2000 \mathrm{~ms}$ or until a response was given. Participants were instructed to respond as quickly and accurately as possible by pressing the buttons 'Yes' or 'No' on a keypad. They were told to select 'Yes' if they believed that the word presented on the screen had emotional content and 'No' if it had no emotional content. After each response or time-out, there was a blank inter-trial of $1000 \mathrm{~ms}$. Languages were blocked. Thus, when the first half of the experiment was finished, notification of the change of language was given. The order of the stimuli within each file was randomized for each participant. The affective decision task was conducted using DMDX (Forster \& Forster, 2003).

At the end of the affective decision task, participants had to conduct a nonverbal filler task for 2 minutes, which consisted of counting backwards from 575 in threes. They were then instructed to write down on paper all the words they could 
remember from those appearing in the affective decision task. They were given five minutes to complete this task.

\section{Results and Discussion}

Since the affective decision task involves a subjective evaluation, we considered that an analysis of accuracy was not appropriate. Hence, only reaction times (RT) were taken into account.

Reaction times. Responses slower than $2000 \mathrm{~ms}$ and faster than $200 \mathrm{~ms}$, as well as RTs that exceeded $2 S D$ of each participant's mean, were removed ( $6.3 \%$ of the total). Analyses were carried out on correct responses only, and a 2 (language) x 3 (emotionality) x 2 (concreteness) factorial ANOVA was used (see Table 3). The three factors were treated as repeated measures in the by-participant analysis.

In the by-items analysis, language was a within-items factor, whereas concreteness and emotionality were between-items factors.

Table 3. Mean RTs (in ms) and percentage of free recall $(\% \mathrm{R})$ in Experiment 1 (standard deviations in parentheses)

\begin{tabular}{|c|c|c|c|c|}
\hline Language & Emotionality & Concreteness & RT & $\% \mathrm{R}$ \\
\hline & & Concrete & 1007 (169) & $13.0(11.6)$ \\
\hline & Positive & & & \\
\hline & & Abstract & 972 (155) & $4.7(6.3)$ \\
\hline & & Concrete & 1057 (215) & $9.6(11.7)$ \\
\hline \multirow[t]{4}{*}{ Catalan } & Negative & & & \\
\hline & & Abstract & 1054 (173) & $2.1(4.2)$ \\
\hline & & Concrete & 949 (162) & $5.6(7.5)$ \\
\hline & Neutral & Abstract & $1008(201)$ & $1.5(3.8)$ \\
\hline
\end{tabular}




\begin{tabular}{|c|c|c|c|c|}
\hline & & Concrete & 993 (155) & 14.5 (11.6) \\
\hline & Positive & Abstract & $981(173)$ & $3.0(5.2)$ \\
\hline & & Concrete & $1064(215)$ & $6.2(7.3)$ \\
\hline \multirow{4}{*}{ Spanish } & & Abstract & $1053(230)$ & $0.6(2.2)$ \\
\hline & & Concrete & 968 (159) & $6.0(9.9)$ \\
\hline & Neutral & & & \\
\hline & & Abstract & 997 (166) & $1.1(3.4)$ \\
\hline
\end{tabular}

There was a main effect of emotionality, $F_{1}(2,72)=11.22, \mathrm{MSE}=23220.63, p$ $<.001, F_{2}(2,137)=6.78, \mathrm{MSE}=24666.66, p=.002$. Pairwise Bonferroni comparisons revealed that negative words $(M=1057, S D=176)$ were responded to significantly more slowly than either positive words $(M=988, S D=126, p<.001)$ or neutral words $(M=985, S D=155, p<.001)$. Furthermore, the interaction between emotionality and concreteness was significant, $F_{l}(2,72)=3.28, \mathrm{MSE}=14075.16, p=.05, F_{2}(2,137)=$ 4.07, MSE $=24666.66, p=.02$. This interaction indicated that, focusing on concrete words, the only significant difference was between negative and neutral words $(p<$ .001). By contrast, with abstract words the only significant difference was between negative and positive words $(p=.004)$.

Free recall. We included in the analysis only those words that were remembered in the language in which they were presented. We conducted a 2 (language) x 3 (emotionality) x 2 (concreteness) repeated-measures ANOVA on the percentage of remembered words (see Table 3 ).

Results revealed a significant effect of concreteness, $F(1,38)=209.14$, MSE = 27.26, $p<.001$, where concrete words $(M=9.2, S D=3.4)$ were better recalled than abstract words $(M=2.2, S D=1.6)$. There was also a significant effect of emotionality, 
$F(2,76)=21.57, \operatorname{MSE}=56.15, p<.001$, where positive words $(M=8.8, S D=4.2)$

were significantly better remembered than both negative words $(M=4.6, S D=3.0, p<$ $.001)$ and neutral words $(M=3.5, S D=3.9, p<.001)$. In addition, the interaction between emotionality and concreteness was significant, $F(2,76)=7.99$, $\mathrm{MSE}=36.99$, $p<.001$.This interaction revealed that the advantage for positive words over negative and neutral words was higher for concrete words (Magnitude of the advantage $=13.89$, $\mathrm{SD}=2.74$ ) than for abstract words (Magnitude of the advantage $=5.23, \mathrm{SD}=1.27, p=$ $.004)$.

The results of this experiment showed a clear effect of emotionality in both the affective decision task and the later free recall task. In the affective decision task, there was a disadvantage for negative words with respect to both positive words (in the abstract conditions) and neutral words (in the concrete conditions). In contrast, in the free recall task there was a superior memory for positive words over their negative and neutral counterparts, this advantage being higher for concrete than for abstract words. It is important to mention that emotionality and concreteness did not interact significantly with language in any of the tasks. Considering that Catalan and Spanish were learned during early childhood in an immersion context, this last result supports the "emotional contexts of learning hypothesis" (Harris et al., 2006). Hence, it is plausible that both Catalan and Spanish words would be linked to the same extent to sensory-motor and emotional information (i.e., they would be embodied, Pavlenko, 2012).

The participants in this experiment, although being proficient early bilinguals, used Catalan more than Spanish in their everyday life. This could have produced a stronger association of Catalan words with emotional contexts, but the results of this Experiment do not suggest that this was the case. However, it might be that differences between languages on emotional processing do not easily emerge in tasks where 
bilinguals are focused on the affective meaning of words or in which a deep level of processing is involved (i.e., as in the tasks used in this experiment). Rather, if these differences exist, they might be more likely to be observed in tasks in which the affective content is processed automatically (Segalowitz et al., 2008; Winskel, 2013). In order to explore this issue, we conducted a second experiment using a task not focused on emotionality (i.e., a LDT).

\section{EXPERIMENT 2}

\section{Method}

Participants. A sample of 40 participants (33 female), aged 18-26 ( $M=19.58$, $S D=2.25$ ) took part in the study. They were undergraduate students at the University Rovira i Virgili who received course credits for participating. Participants signed an informed consent form before starting the experiment. They completed the same language history questionnaire as participants in Experiment 1. Participants were exposed to Catalan from birth, and their average age of exposure to Spanish was 2.13 years $(\mathrm{SD}=2.45)$. Table 1 shows that, as with the previous experiment, participants were highly proficient in both Catalan and Spanish, although more proficient in Catalan $(M=6.99, S D=0.06)$ than in Spanish $(M=6.64, S D=0.55) ; t(39)=4.04, p<.001$. Again, according to the questionnaire, Catalan was the preferred language for these participants and the one they used more frequently.

Design and materials. The design and experimental materials were the same as in Experiment 1, the only difference being that in this case the set of neutral, filler words was not included. Instead, an additional pool of 144 Spanish words and their Catalan translations were selected to serve as base words to create a set of nonwords for the purposes of the LDT. Thus, 144 Spanish nonwords and 144 Catalan nonwords were created by changing 1 or 2 letters of these base words. 
Procedure. The procedure was very similar to the one used in Experiment 1, the only difference being that participants were asked to perform a LDT. Thus, they were instructed to press the 'Yes' button if they considered that the string of letters presented on the screen was a real word (i.e., a Catalan or Spanish word, depending on the block), and 'No' if they considered that it was not a real word.

At the end of the LDT, as in Experiment 1, participants conducted a non-verbal filler task for 2 minutes. Then, they were given 5 minutes to write down on paper all the words that they could remember from those appearing in the LDT.

\section{Results and Discussion}

Reaction times. Responses slower than 2000 ms and faster than 200 ms, as well as RTs that exceeded $2 S D$ of each participant's mean, were excluded from the analyses ( $4.68 \%$ of the total). In addition, the criterion for rejecting a participant's data was that their accuracy rates were lower than $80 \%$, although no participant was excluded for this reason. Analyses were carried out on correct responses only. The results are presented in Table 4.

Table 4. Mean RTs (in $\mathrm{ms})$, percentage of errors $(\% \mathrm{E})$, and percentage of free recall $(\% \mathrm{R})$ in Experiment 2 (standard deviations in parentheses)

\begin{tabular}{|c|c|c|c|c|c|}
\hline Language & Emotionality & Concreteness & RT & $\% \mathrm{E}$ & $\% \mathrm{R}$ \\
\hline & & Concrete & 723 (113) & $1.9(3.6)$ & $10.0(10.0)$ \\
\hline & & Abstract & $736(114)$ & $5.7(7.8)$ & $2.3(4.2)$ \\
\hline & & Concrete & 746 (113) & $4.2(5.4)$ & $4.2(5.7)$ \\
\hline & Negative & & & & \\
\hline & & Abstract & 768 (107) & $8.4(7.2)$ & $1.3(3.6)$ \\
\hline
\end{tabular}




\begin{tabular}{|c|c|c|c|c|c|}
\hline & \multirow{2}{*}{ Neutral } & Concrete & $723(112)$ & $8.4(10.0)$ & $5.4(9.4)$ \\
\hline & & Abstract & 732 (116) & $6.2(7.6)$ & $0.8(2.5)$ \\
\hline \multirow{7}{*}{ Spanish } & \multirow{2}{*}{ Positive } & Concrete & 717 (104) & $2.6(5.1)$ & $6.9(9.6)$ \\
\hline & & Abstract & $722(115)$ & $4.4(5.4)$ & $3.5(5.6)$ \\
\hline & \multirow{2}{*}{ Negative } & Concrete & $732(114)$ & $3.2(5.4)$ & $2.1(4.5)$ \\
\hline & & Abstract & $765(125)$ & $5.7(6.8)$ & $1.0(3.4)$ \\
\hline & \multirow{3}{*}{ Neutral } & Concrete & $716(112)$ & $4.3(5.8)$ & $1.5(3.2)$ \\
\hline & & & & & \\
\hline & & Abstract & $722(102)$ & $4.6(6.0)$ & $2.1(4.1)$ \\
\hline
\end{tabular}

A 2 (language) x 3 (emotionality) x 2 (concreteness) factor ANOVA was conducted on RTs. There was a main effect of emotionality, $F_{l}(2,78)=12.96, \mathrm{MSE}=$ $3371.50, p<.001, F_{2}(2,138)=3.68, \mathrm{MSE}=9432.16, p=.03$, where negative words $(M$ $=752, S D=102)$ were responded to more slowly than both positive words $(M=725$, $S D=100, p<.001)$ and neutral words $(M=723, S D=98, p<.001)$. The main effect of concreteness was also significant in the analysis by participants, $F_{l}(1,39)=9.52$, MSE $=2782.50, p=.004, F_{2}(1,138)=2.55, \mathrm{MSE}=9432.16, p=.11$, revealing that participants responded faster to concrete words $(M=726, S D=97)$ than to abstract words $(M=741, S D=100)$.

Accuracy. We conducted an ANOVA with the same factors as in the analysis of RTs. There was a main effect of language, significant only by participants, $F_{l}(1,39)=$ $8.69, \mathrm{MSE}=38.34, p=.005, F_{2}(1,138)=3.08, \mathrm{MSE}=70.19, p=.08$, showing that participants made more errors in Catalan $(M=5.8, S D=3.9)$ than in Spanish $(M=4.1$, $S D=3.1)$. Emotionality was also significant in the analysis by participants, $F_{1}(2,78)=$ $7.00, \mathrm{MSE}=31.25, p=.002, F_{2}(2,138)=1.62, \mathrm{MSE}=70.19, p=.20$, in that positive 
words $(M=3.7, S D=2.8)$ were responded to more accurately than both negative words $(M=5.4, S D=3.7, p=.006)$ and neutral words $(M=5.9, S D=4.8, p=.003)$. There was also a main effect of concreteness, significant only in the by-participants analysis, $F_{1}(1,39)=10.06, \mathrm{MSE}=36.81, p=.003, F_{2}(1,138)=3.33, \mathrm{MSE}=70.19, p=.07$, showing that concrete words $(M=4.1, S D=3.1)$ produced fewer errors than abstract words $(M=5.9, S D=3.9)$. Finally, there was a significant interaction between emotionality and concreteness, although only in the analysis by participants, $F_{l}(2,78)=$ $5.18, \mathrm{MSE}=41.77, p=.008, F_{2}(2,138)=1.89, \mathrm{MSE}=70.19, p=.15$. This interaction indicated that the higher accuracy for emotional words was restricted to positive concrete words $(p=.001)$, whereas neither negative concrete words nor abstract emotional words showed higher accuracy than neutral words.

Free recall. The percentage of correctly recalled words was analysed with a 2 (language) x 3 (emotionality) x 2 (concreteness) repeated-measures ANOVA. There was a significant effect of emotionality, $F(2,78)=19.40, \mathrm{MSE}=31.71, p<.001$, as positive words $(M=5.7, S D=3.2)$ were better remembered than negative $(M=2.1, S D$ $=2.3, p<.001)$ or neutral words $(M=2.4, S D=2.4, p<.001)$. The main effect of concreteness was also significant, $F(1,39)=44.37$, MSE $=27.00, p<.001$, where concrete words $(M=5.0, S D=2.4)$ were better remembered than abstract words $(M=$ $1.8, S D=1.6)$. In addition, there were two significant interactions: The languageconcreteness interaction, $F(1,39)=12.86, \mathrm{MSE}=34.04, p<.001$, showed that there was a difference between concrete and abstract words in Catalan $(M=6.53, S D=0.85$, and $M=1.46, S D=0.29$ for concrete and abstract words, respectively, $p<.001$ ), but not in Spanish $(M=3.47, S D=0.64$, and $M=2.22, S D=0.48$ for concrete and abstract words, respectively, $p=0.06)$. The second significant interaction was between emotionality and concreteness, $F(2,78)=5.60, \mathrm{MSE}=29.84, p=.005$. This interaction 
indicated that, when words were concrete, positive words $(M=8.44, S D=0.84)$ were better remembered than both negative $(M=3.12, S D=0.57, p<.001)$ or neutral words $(M=3.44, S D=0.74, p=.001)$. By contrast, regarding abstract words, positive ones $(M$ $=2.92, S D=0.49)$ were better remembered than negative ones $(M=1.15, S D=0.36, p$ $=.03)$, but they were not superior to neutral words $(M=1.46, S D=0.44, p=.09)$.

The results of this experiment showed that both concreteness and emotionality had a significant effect in the LDT as well as in the later free recall task. Indeed, concrete words were responded to faster and more accurately in the LDT and better remembered in the free recall task. The concreteness advantage in the memory task was observed only in Catalan (i.e., the dominant language). This interaction between language and concreteness was not found in Experiment 1. A possible reason of this discrepancy is the different encoding tasks across the experiments (i.e., an affective decision task in Experiment 1 vs. a lexical decision task in Experiment 2), and a potential explanation here is that the deeper processing of words in Experiment 1 does not enable differences in concreteness to emerge between the two languages.

Concerning emotionality, the direction of the effect was the same as in Experiment 1, namely, that participants responded more slowly to negative words in the LDT, whereas they remembered more positive words. In this experiment, an advantage for positive words was also observed in the data on accuracy in the LDT. As in Experiment 1, the effect of emotionality was modulated by concreteness in some cases (i.e., $\% \mathrm{E}$ in the LDT and percentage of remembered words in the free recall data), suggesting that the effects of emotionality were higher in concrete words than in abstract words. Importantly, the emotionality effect was not modulated by language, either in the LDT or in the free recall task. Therefore, the lack of differences between languages in emotional processing observed in Experiment 1 was replicated in this 
experiment. Hence, a greater lifelong frequency of use of Catalan over Spanish might not be enough to produce differences in affective processing between these two languages, which could be because these participants acquired both languages during early childhood while being immersed in a Catalan-Spanish environment. In contrast, a different result would be expected if we tested a non-native language, one acquired and used in an instructional setting. To explore this issue further, we conducted Experiment 3, in which Catalan-Spanish bilinguals who were also proficient in English performed a LDT in Spanish and English.

\section{EXPERIMENT 3}

Method

Participants. A sample of 51 participants (40 females), aged 18-41 ( $M=21.47$, $S D=4.26)$ took part in the study. They were undergraduate students at the University Rovira i Virgili and received course credits for participating. They signed an informed consent form before starting the experiment. They completed a language history questionnaire in order to assess their proficiency in Catalan, Spanish, and English. Participants in Experiment 3 were highly proficient Catalan-Spanish bilinguals who were also proficient in English, a language that they acquired later (Mage of acquisition $=5.86, \mathrm{SD}=2.22$ ). As can be seen from Table 1 , the average level of proficiency in English $(\mathrm{M}=5.11, \mathrm{SD}=0.20)$ was lower than in Spanish $(\mathrm{M}=6.76, \mathrm{SD}=0.15), \mathrm{t}(50)$ $=13.44, \mathrm{p}<.001$ or Catalan $(\mathrm{M}=6.78, \mathrm{SD}=0.12), \mathrm{t}(50)=16.30, \mathrm{p}<.001$. Participants were also asked about the type of context in which they acquired English as well as their experience abroad. All had acquired English in an instructional setting. Furthermore, 15 participants had lived in an English speaking country for a period of less than 10 months; ten of these for less than three months, and 5 for more than 4 
months. For the purposes of this experiment, we considered Spanish as the native language of these participants, and English as their non-native language.

Design and materials. The design and experimental materials were the same as in Experiment 2, the only difference being that in this case the Catalan words were replaced by their English translations (see the Appendix). We checked that the English words differed in the manipulated variables and were matched in the controlled variables. The values of valence and arousal were obtained from Warriner, Kuperman, and Brysbaert (2013), the values of the lexical variables from NIM (Guasch et al., 2013), and the values of concreteness from Brysbaert, Warriner, and Kuperman (2014). A 2x3 factorial ANOVA with concreteness (concrete and abstract words) and emotionality (positive, negative, and neutral words) showed that concrete and abstract English words were significantly different in concreteness, $F(1,138)=144.72, p<$ .001. In addition, positive, negative, and neutral words were significantly different in valence $F(2,138)=262.91, p<.001$, and arousal $F(2,138)=57.58, p<.001$. Finally, 144 English nonwords were created by changing 1 or 2 letters from a set of 144 base English words.

Procedure. The procedure was exactly the same as the one used in Experiment 2.

\section{Results and Discussion}

Reaction times. Responses slower than $2000 \mathrm{~ms}$ and faster than $200 \mathrm{~ms}$ were excluded from the analysis. RTs that exceeded $2 S D$ of each participant's mean were also rejected (5\% of the total). Moreover, participants with accuracy rates lower than $80 \%$ in the English words were also excluded, and this led to the exclusion of 12 participants. Furthermore, we removed 7 English items (and their Spanish translations) from the analysis in that they yielded more than $70 \%$ of errors. A 2 (language) x 3 
(emotionality) x 2 (concreteness) factor ANOVA was conducted on RTs and on $\% \mathrm{E}$ (see Table 5).

Table 5. Mean RTs (in ms), percentage of errors $(\% \mathrm{E})$, and percentage of free recall $(\% \mathrm{R})$ in Experiment 3 (standard deviations in parentheses)

\begin{tabular}{|c|c|c|c|c|c|}
\hline Language & Emotionality & Concreteness & RT & $\% \mathrm{E}$ & $\% \mathrm{R}$ \\
\hline \multirow{6}{*}{ Spanish } & \multirow{2}{*}{ Positive } & Concrete & $600(91)$ & $2.0(5.0)$ & $9.6(10.4)$ \\
\hline & & Abstract & 607 (94) & $4.0(6.8)$ & $3.0(5.3)$ \\
\hline & \multirow{2}{*}{ Negative } & Concrete & $604(93)$ & $0.5(2.0)$ & $5.0(7.0)$ \\
\hline & & Abstract & $631(102)$ & $45(56)$ & $25(68)$ \\
\hline & \multirow{2}{*}{ Neutral } & Concrete & $602(91)$ & $3.0(6.0)$ & $2.1(4.9)$ \\
\hline & & Abstract & $618(104)$ & $2.9(5.1)$ & $0.9(3.5)$ \\
\hline \multirow{6}{*}{ English } & \multirow{2}{*}{ Positive } & Concrete & $629(79)$ & $5.8(7.0)$ & $11.5(9.4)$ \\
\hline & & Abstract & $645(95)$ & $4.5(6.4)$ & $6.7(6.0)$ \\
\hline & \multirow{2}{*}{ Negative } & Concrete & $650(98)$ & $17.6(13.4)$ & $7.4(8.4)$ \\
\hline & & Abstract & $660(95)$ & $10.6(11.5)$ & $3.6(5.0)$ \\
\hline & \multirow{2}{*}{ Neutral } & Concrete & $672(96)$ & $15.5(12.0)$ & $5.6(8.1)$ \\
\hline & & Abstract & $642(97)$ & $5.0(7.1)$ & $5.3(7.6)$ \\
\hline
\end{tabular}

There was a main effect of language, $F_{l}(1,78)=28.28, \mathrm{MSE}=6504.17, p<$ $.001, F_{2}(1,131)=59.52, \mathrm{MSE}=2991.69, p<.001$, as Spanish words were responded faster $(M=610, S D=96)$ than English words $(M=650, S D=94)$. The factor 
emotionality was also significant in the analysis by participants, $F_{I}(2,78)=11.24$, MSE $=1084.16, p<.001, F_{2}(2,131)=1.71, \mathrm{MSE}=6500.60, p=.18$. Pairwise comparisons showed that participants responded faster to positive words $(M=620, S D=91)$ than to both negative words $(M=636, S D=99, p<.001)$ and neutral words $(M=634, S D=$ $100, p=.001)$. The main effect of concreteness was also significant in the analysis by participants, $F_{l}(1,39)=6.23, \mathrm{MSE}=1085.72, p=.02, F_{2}(1,131)=0.31, \mathrm{MSE}=$ $6500.60, p=.58$, revealing that participants responded faster to concrete words $(M=$ $626, S D=95)$ than to abstract words $(M=634, S D=99)$. Three significant interactions were found in the analysis by participants: (1) a language by concreteness interaction, $F_{1}(1,39)=8.27, \mathrm{MSE}=1119.35, p=.006, F_{2}(1,131)=2.77, \mathrm{MSE}=2991.69, p=.09$, (2) an emotionality by concreteness interaction, $F_{l}(2,78)=6.16$, MSE $=1112.46, p=$ $.003, F_{2}(2,131)=1.67, \mathrm{MSE}=6500.60, p=.19$, and (3) a three way interaction between language, concreteness and emotionality, $F_{l}(2,78)=5.72, \mathrm{MSE}=1329.54, p$ $=.005, F_{2}(1,131)=2.08, \mathrm{MSE}=2991.69, p=.13$. The language-concreteness interaction (1) showed that there was a concreteness advantage for Spanish words $(M=$ $602, \mathrm{SD}=91$ and $M=619, \mathrm{SD}=100$, for concrete and abstract words, respectively, $\mathrm{p}<$ $.001)$, but not for English words $(M=650, \mathrm{SD}=93$ and $M=649, \mathrm{SD}=95$, for concrete and abstract words, respectively, $\mathrm{p}>.77$ ). The emotionality-concreteness interaction (2) revealed that when words were concrete there was a facilitation for positive words $(M=$ $614, \mathrm{SD}=86)$ compared to neutral words $(M=637, \mathrm{SD}=99, \mathrm{p}<.001)$. However, when words were abstract, participants took longer to respond to negative words $(M=$ $646, \mathrm{SD}=99)$ than to both positive words $(M=626, \mathrm{SD}=96, \mathrm{p}<.005)$ and neutral words $(M=630, \mathrm{SD}=101, \mathrm{p}<.05)$. Finally, the three-way interaction (3) indicated that the effects of emotionality for English words only occurred with concrete words, where there was a facilitation for both positive $(M=629, \mathrm{SD}=79, \mathrm{p}<.001)$ and negative 
words $(M=650, \mathrm{SD}=98, \mathrm{p}=.003)$ compared to neutral words $(\mathrm{M}=672, \mathrm{SD}=96)$. Nevertheless, in Spanish the effects of emotionality were only observed in abstract words, where participants responded more slowly to negative words $(M=631, \mathrm{SD}=$ 102) than to positive ones $(M=607, \mathrm{SD}=94, \mathrm{p}=.003)$.

Accuracy. We conducted an ANOVA with the same factors as the analysis of RTs. There was a main effect of language, $F_{l}(1,39)=70.44, \operatorname{MSE}=83.49, p<.001$, $F_{2}(1,131)=28.96, \mathrm{MSE}=139.13, p<.001$, showing that participants made more errors in English $(M=9.8, S D=11.1)$ than in Spanish $(M=2.8, S D=5.4)$.

Emotionality was also significant in the analysis by participants, $F_{1}(2,78)=12.34$, $\mathrm{MSE}=58.59, p<.001, F_{2}(2,131)=2.60, \mathrm{MSE}=167.83, p=.08$. Pairwise comparisons revealed that positive words $(M=4.1, S D=6.4)$ were responded to more accurately than both negative words $(M=8.3, S D=11.3, p<.001)$ and neutral words $(M=6.6, S D=9.5, p=.01)$. There was also a main effect of concreteness, significant in the by-participants analysis, $F_{l}(1,39)=14.61, \mathrm{MSE}=36.56, p<.001, F_{2}(1,131)=$ $1.80, \operatorname{MSE}=167.83, p=.18$, showing that concrete words $(M=7.4, S D=10.8)$ produced more errors than abstract words $(M=5.3, S D=7.7)$.

Importantly, four significant interactions were also found: (1) A languageemotionality interaction, $F_{l}(2,78)=16.76, \mathrm{MSE}=53.93, p<.001, F_{2}(2,131)=3.66$, MSE $=139.13, p=.03,(2)$ a language-concreteness interaction, $F_{l}(1,39)=45.95$, $\mathrm{MSE}=44.51, p<.001, F_{2}(1,131)=8.37, \mathrm{MSE}=139.13, p=.004,(3)$ a concreteness emotionality interaction, significant in the analysis by participants, $F_{l}(2,78)=8.06$, $\mathrm{MSE}=41.41, p=.001, F_{2}(2,131)=1.42, \mathrm{MSE}=167.83, p=.24$; and $(4)$ a three-way interaction between language, concreteness and emotionality, which was significant in the analysis by participants, $F_{1}(2,78)=3.70, \mathrm{MSE}=47.92, p=.03, F_{2}(2,131)=0.73$, MSE $=139.13, p=.48$. The language-emotionality interaction (1) showed that the 
emotionality effect was restricted to English words, where participants were more accurate with positive words $(M=5.1, \mathrm{SD}=6.7)$ than with negative $(M=14.1, \mathrm{SD}=$ $12.9, \mathrm{p}<.001)$ and neutral words $(M=10.2, \mathrm{SD}=11.1, \mathrm{p}=.001)$. Furthermore, they made fewer errors with neutral words than with negative words $(p<.05)$. The languageconcreteness interaction (2) showed that while participants were more accurate with Spanish concrete words $(M=1.8, \mathrm{SD}=4.7)$ than with Spanish abstract words $(M=3.8$, $\mathrm{SD}=5.9, \mathrm{p}<.001)$, the pattern reversed with English words, where participants were more accurate with abstract words $(M=6.7, \mathrm{SD}=9.0)$ than with concrete words $(M=$ 12.9, $\mathrm{SD}=12.2, \mathrm{p}<.001)$. The interaction between concreteness and emotionality (3) revealed that participants were more accurate with positive concrete words $(M=3.9$, $\mathrm{SD}=6.4)$ than with their negative $(M=9.0, \mathrm{SD}=12.8, \mathrm{p}<.001)$ and neutral $(M=9.2$, $\mathrm{SD}=11.3, \mathrm{p}<.001)$ counterparts. However, with abstract words, participants were less accurate with negative words $(M=7.6, \mathrm{SD}=9.5)$ than with both positive words $(M=$ $4.3, \mathrm{SD}=6.5, \mathrm{p}=.01)$ and neutral words $(M=4.0, \mathrm{SD}=6.2, \mathrm{p}=.02)$. Finally, the three-way interaction (4) showed that the differences were only significant for English words, where participants were more accurate when responding to positive English concrete words $(M=5.8, \mathrm{SD}=7.0)$ than to their negative $(M=17.6, \mathrm{SD}=13.4, \mathrm{p}<$ $.001)$ and neutral counterparts $(M=15.5, \mathrm{SD}=12.0, \mathrm{p}<.001)$. With abstract words, there was a higher number of errors for negative words $(M=10.6, \mathrm{SD}=11.5)$ compared to both positive $(M=4.5, \mathrm{SD}=6.4, \mathrm{p}=.004)$ and neutral words $(M=5.0, \mathrm{SD}=7.1, \mathrm{p}=$ $.02)$.

Free recall. As in Experiments 1 and 2, the percentage of correctly recalled words was analysed with a 2 (language) x 3 (emotionality) x 2 (concreteness) repeatedmeasures ANOVA (see Table 5). There was a significant effect of language, $F(1,39)=$ 13.29, $\mathrm{MSE}=72.57, p=.001$, showing that English words $(\mathrm{M}=6.7, \mathrm{SD}=7.9)$ were 
better remembered than Spanish words $(\mathrm{M}=3.8, \mathrm{SD}=7.2)$. The effect of emotionality was also significant, $F(2,78)=21.04, \mathrm{MSE}=36.02, p<.001$, as positive words $(M=$ $7.7, S D=8.6)$ were better remembered than both negative $(M=4.6, S D=7.1, p<.001)$ and neutral words $(M=3.5, S D=6.6, p<.001)$. There was also a significant effect of concreteness $F(1,39)=28.23, \mathrm{MSE}=42.98, p<.001$, where concrete words $(M=6.9$, $\mathrm{SD}=8.7)$ were better remembered than abstract words $(M=3.7, S D=6.1)$. Finally, the interaction between emotionality and concreteness also reached statistical significance, $F(2,78)=6.81, \mathrm{MSE}=35.39, p=.002$. This interaction revealed that the effect of emotionality was restricted to concrete words, where positive words $(M=10.5, S D=$ 9.9) were better remembered than both negative $(M=6.2, S D=7.8, p<.001)$ and neutral ones $(M=3.9, S D=6.9, p<.001)$. The effect was not modulated by language. The results of this experiment revealed that language had a significant effect in the LDT and in free recall. Regarding the LDT, there was a clear advantage for Spanish words over English ones (both in RTs and accuracy), in accordance with the higher proficiency of participants in Spanish than in English. In terms of free recall, English words were better remembered than Spanish words. This advantage for English words might be due to their higher distinctiveness in memory (Hunt \& Worthen, 2006) or to the higher effort and resources devoted to their processing during the encoding task (i.e., the LDT). Similarly to the results obtained in Experiment 2, concrete words were processed faster in the LDT and better remembered than abstract words. Importantly, the effect of emotionality was also significant: In this experiment, positive words showed a facilitation over negative and neutral words in both tasks.

For the purposes of this study, the most relevant findings are those indicating that some of the experimental effects were modulated by language. Hence, the interaction between language and concreteness in the LDT (both in RTs and \%E) 
reveals that the typical facilitative concreteness advantage (e.g., Binder, Westbury, McKiernan, Possing, \& Medler, 2005; Romani, MacAlpine, \& Martin, 2008) was only observed in the native language. This result supports findings from Foroni (2015) and Jończyk (2016), suggesting a weaker link between words in the non-native language and sensory-motor information (i.e., disembodiment) compared to the native language. The three-way interaction was also significant (both in RTs and \%E), indicating that the processing of emotional words was not equivalent in the native and the non-native language. Indeed, RTs showed a facilitation for positive and negative concrete words in English, whereas there was an interference for negative abstract words in Spanish. On the one hand, this finding supports the proposal by Kousta et al. (2011) concerning the greater role of emotionality in the processing of abstract words in regard to concrete ones, although this result was only observed for words in the native language. On the other hand, it is important to note that the pattern of results with negative words was the opposite when considering the native language (i.e., interference) and the non-native language (i.e., facilitation). This latter result is in line with previous studies that have found differences between the two languages in the processing of negative words (Conrad et al., 2011; Sheikh \& Titone, 2016). Finally, there was an unexpected finding with the \%E. Namely, the interaction between concreteness and emotionality was restricted to English. This may have been produced by the high percentage of errors in English, in that there is more room for such effects to become apparent when the percentage of errors is high (English) than when it is small (Spanish). 


\section{GENERAL DISCUSSION}

The present study aimed to investigate whether the emotional content of words is processed in a similar way in the different languages of bilinguals, by testing the effects of the characteristics of the words, the type of task, and language status. To that end, we orthogonally manipulated the emotional content of words and their concreteness. We tested Catalan-Spanish bilinguals performing an affective decision task and a lexical decision task in Catalan and Spanish, as well as Catalan-Spanish bilinguals who were proficient in English performing a lexical decision task in Spanish and English. Additionally, all participants performed an unexpected free recall task at the end of the experiments. The results revealed that the direction of the emotional effects varied across tasks. Importantly, the emotional effects were modulated by language only when participants performed the task in Spanish and English, but not when they performed the task in Catalan and Spanish.

A previous study conducted with Catalan-Spanish bilinguals (Ferré et al., 2010), using a task that focused on emotionality, failed to find differential emotional processing in the two languages. According to Segalowitz et al. (2008) and Winskel (2013), the reason for differences in emotional intensity between words in the native and the non-native language might be that bilinguals do not process the affective valence of words in the non-native language as automatically as that of words in the native language. Therefore, we reasoned that it would be easier to observe differences between languages in tasks tapping into automatic processing than in tasks involving affective or more elaborate processing. For that reason, we tested Catalan-Spanish bilinguals in a task involving affective processing (Experiment 1) as well as in one which did not involve conscious affective processing (Experiment 2). Both tasks were followed by a free recall task. The results of these experiments showed a disadvantage 
in processing for negative words (affective categorization task and LDT in Experiments 1 and 2) and an advantage for positive words (LDT in Experiment 2 and free recall in Experiments 1 and 2). These findings are in line with previous studies with monolingual speakers reporting an advantage for positive words (e.g., Hoffman, Kuchinke, Tamm, Võ, \& Jacobs, 2009; Kousta et al., 2009) and a disadvantage for negative words (e.g., Estes \& Adelman, 2008; MacKay et al., 2004). Similarly to the effects of emotionality found in the LDT, the effects of concreteness (i.e., a facilitation for the processing of concrete words over abstract words) are also in line with the literature with monolinguals (Binder et al., 2005).

The most relevant finding in Experiments 1 and 2 is the lack of interaction between emotionality and language. This result suggests that highly proficient CatalanSpanish bilinguals, who acquired both languages in early childhood in an immersion context, process the emotional content of both languages similarly. This is true even when they have used Catalan more than Spanish throughout their life (i.e., Catalan words might have had more opportunities to be attached to emotional situations). Also, the pattern of results is the same regardless of the type of task (i.e., focused in emotional content or not). This result contrasts with the pattern of findings observed in Experiment 3, when participants performed the task in Spanish and English. The interactions by language found in Experiment 3 suggest that emotionality and concreteness are not processed in the same way in the two languages. Indeed, when looking at the RTs, the effect of concreteness was only significant in the native language of the speakers (Spanish), the effect being absent in their non-native language (English). Moreover, the concreteness effect reversed for English words in the $\% \mathrm{E}$. These results suggest that bilinguals might not ground non-native words in sensorimotor experiences to the same extent as native words (Foroni, 2015; Jończyk, 2016; Pavlenko, 2012). In addition, the 
triple interaction between language, emotionality and concreteness indicated that the effects of concreteness and emotionality varied depending on the language in which words were presented. When words were presented in Spanish, the effect of emotionality in RTs was only significant for abstract words, yet this pattern was reversed when the words were presented in English, where the effects of emotionality only occurred for concrete words. This suggests that the preferential modulation of processing by emotionality for abstract words hypothesized by Kousta et al. (2011) was observed only in the native language. Thus, it indicates that abstract words in the nonnative language might not be as strongly linked to emotional information as words in the native language. Furthermore, the pattern of results for negative words was different across languages. That is, there was a facilitation for both positive and negative words in English, whereas there was an interference for negative words in Spanish. This last result is in line with past studies finding differences between languages in the processing of negative words (Conrad et al., 2011; Sheikh \& Titone, 2016; Wu \& Thierry, 2012).

The above pattern of results is important because it shows that language status is a relevant factor in emotional word processing. Therefore, differences between both languages are observed when the non-native language was acquired in an instructional setting and bilinguals were immersed in their native language (Experiment 3), but not when they acquired both languages in an immersion context and remain in that context (Experiments 1 and 2). However, before concluding that the different pattern of results of Experiments 1 and 2 with respect to Experiment 3 are exclusively produced by the context of language acquisition and use, there is an additional factor that should be considered: the cognate status of the words (i.e., the degree of formal similarity between translation equivalents). It is widely acknowledged that cognate status affects word 
processing (see Dijkstra, Miwa, Brummelhuis, Sappelli, \& Baayen, 2010, for a review). Spanish and Catalan are both Romance languages with a high number of cognate translations. Therefore, the lack of modulation of the experimental effects by language in Experiments 1 and 2 might be produced by the large number of cognate words in the experimental materials ( $85 \%$ of the total). In contrast, in Experiment 3, there were only $48 \%$ of cognate words, the number of cognates between Spanish and English being far lower. In order to see whether cognate status has affected the results of Experiment 3 , we analyzed cognate and non-cognate words separately. These analyses revealed that, for both $\% \mathrm{E}$ in the LDT and the free recall task, results were very similar for cognates and non-cognates. In contrast, RT data showed that the interactions of emotional content and concreteness by language were obtained only with non-cognate words, not with cognate words. These results suggest that, although cognate status cannot entirely account for the findings of this study, it might have contributed to some extent. Further research is needed in which cognate status is experimentally manipulated to ascertain its role in differences in emotional processing between languages.

A final result worth mentioning here is that the task employed can determine the effects obtained. While we found a modulation of the emotional effects by language in the LDT in Experiment 3, there was no such a modulation in the subsequent free recall task. In fact, the results of the free recall task are very consistent across experiments. Indeed, in the three experiments we found an advantage for positive and concrete words in memory, in line with monolingual studies (Ferré, 2003; Kensinger, 2008), and also an interaction with concreteness. These results do not depend on the characteristics of the initial task (i.e., comparison of Experiments 1 and 2) or the language status (i.e., comparison of Experiments 2 and 3). Hence, researchers looking for an emotional modulation by language should rely more on tasks tapping into early lexical access than 
those tapping into memory processes, in line with studies that have reported differences between the native and the non-native language in tasks tapping the automatic processing of emotional information (Segalowitz et al., 2008; Winskel, 2013).

To sum up, the present study aimed to investigate whether the emotional content is processed similarly in the two languages of bilinguals by testing the effects of word concreteness, valence, task type, and language status. Our findings suggest that the emotional processing of words has the same characteristics in both languages only when bilinguals acquired them in early childhood in an immersion environment and continued to use both on a daily basis, even when one language was used more than the other. In such cases, the effects of emotionality occur without any modulation of language. However, when differences exist (i.e., when the non-native language was acquired after early childhood in an instructional setting and when bilinguals are immersed in the native language) the effect of emotionality and concreteness varies as a function of language. Ultimately, we also found that the type of task used is key to determining and understanding the direction of the results. Hence, the present findings contribute to a better understanding of emotional word processing in bilinguals. 


\section{REFERENCES}

Altarriba, J., \& Basnight-Brown, D. M. (2010). The representation of emotion vs. emotion-laden words in English and Spanish in the Affective Simon Task. International Journal of Bilingualism, 1367006910379261.

Anooshian, L. J., \& Hertel, P. T. (1994). Emotionality in free recall: Language specificity in bilingual memory. Cognition \& Emotion, 8, 503-514.

Binder, J. R., Westbury, C. F., McKiernan, K. A., Possing, E. T., \& Medler, D. A. (2005). Distinct brain systems for processing concrete and abstract concepts. Journal of Cognitive Neuroscience, 17, 905-917.

Brysbaert, M., Warriner, A. B., \& Kuperman, V. (2014). Concreteness ratings for 40 thousand generally known English word lemmas. Behavior Research Methods, 46, 904-911.

Caldwell-Harris, C. L. (2014). Emotionality differences between a native and foreign language: theoretical implications. Frontiers in Psychology, 5, 1055.

Caldwell-Harris, C. L., \& Ayçiçeği-Dinn, A. (2009). Emotion and lying in a non-native language. International Journal of Psychophysiology, 71, 193-204.

Caldwell-Harris, C. L., Tong, J., Lung, W., \& Poo, S. (2011). Physiological reactivity to emotional phrases in Mandarin-English bilinguals. International Journal of Bilingualism, 15, 329-352.

Chen, P., Lin, J., Chen, B., Lu, C., \& Guo, T. (2015). Processing emotional words in two languages with one brain: ERP and fMRI evidence from Chinese-English bilinguals. Cortex, 71, 34-48.

Colbeck, K. L., \& Bowers, J. S. (2012). Blinded by taboo words in L1 but not L2. Emotion, 12, 217. 
Conrad, M., Recio, G., \& Jacobs, A. (2011). The time course of emotion effects in first and second language processing: A cross-cultural ERP study with GermanSpanish bilinguals. Frontiers in Psychology, 2, 351.

Degner, J., Doycheva, C., \& Wentura, D. (2012). It matters how much you talk: On the automaticity of affective connotations of first and second language words. Bilingualism: Language and Cognition, 15, 181-189.

Dijkstra, T., Miwa, K., Brummelhuis, B., Sappelli, M., \& Baayen, H. (2010). How cross-language similarity and task demands affect cognate recognition. Journal of Memory and language, 62(3), 284-301.

Duchon, A., Perea, M., Sebastián-Gallés, N., Martí, A., \& Carreiras, M. (2013). EsPal: One-stop shopping for Spanish word properties. Behavior Research Methods, 45, 1246-1258.

Eilola, T., \& Havelka, J. (2011). Behavioral and physiological responses to the emotional and taboo Stroop tasks in native and non-native speakers of English. International Journal of Bilingualism, 15, 353-369.

Eilola, T., Havelka, J., \& Sharma, D. (2007). Emotional activation in the first and second language. Cognition \& Emotion, 21, 1064-1076.

Estes, Z., \& Adelman, J. S. (2008). Automatic vigilance for negative words is categorical and general. Emotion, 8, 453-457.

Estes, Z., \& Verges, M. (2008). Freeze or flee? Negative stimuli elicit selective responding. Cognition, 108, 557-565.

Ferré, P. (2003). Effects of level of processing on memory for affectively valenced words. Cognition \& Emotion, 17, 859-880. 
Ferré, P., Fraga, I., Comesaña, M., \& Sánchez-Casas, R. (2015). Memory for emotional words: The role of semantic relatedness, encoding task and affective valence. Cognition and Emotion, 29, 1401-1410.

Ferré, P.; García, T.; Fraga, I.; Sánchez-Casas, R.; Molero, M. (2010). Memory for emotional words in bilinguals: Do words have the same emotional intensity in the first and in the second language? Cognition and Emotion, 24, 760-785.

Ferré, P., Sánchez-Casas, R., \& Fraga, I. (2013). Memory for emotional words in the first and the second language: Effects of the encoding task. Bilingualism: Language and Cognition, 16, 495-507.

Foroni, F. (2015). Do we embody second language? Evidence for "partial" simulation during processing of a second language. Brain and Cognition, 99, 8-16.

Forster, K. I., \& Forster, J. C. (2003). DMDX: A Windows display program with millisecond accuracy. Behavior Research Methods, Instruments, \& Computers, $35,116-124$.

Guasch, M., Boada, R., Ferré, P., \& Sánchez-Casas, R. (2013). NIM: A Web-based Swiss army knife to select stimuli for psycholinguistic studies. Behavior Research Methods, 45, 765-771.

Guasch, M., Ferré, P., \& Fraga, I. (2015). Spanish norms for affective and lexicosemantic variables for 1,400 words. Behavior Research Methods, 48, 1358-1369.

Harris, C. L., Ayçiçeği, A., \& Gleason, J. B. (2003). Taboo words and reprimands elicit greater autonomic reactivity in a first language than in a second language. Applied Psycholinguistics, 24, 561-579.

Harris, C. L., Gleason, J. B., \& Ayçiçeği, A. (2006). When is a first language more emotional? Psychophysiological evidence from bilingual speakers. In A. Pavlenko 
(Ed.), Bilingual Minds: Emotional Experience, Expression, and Representation (pp. 257-283). Clevedon: Multilingual Matters.

Hofmann, M. J., Kuchinke, L., Tamm, S., Võ, M. L. H., \& Jacobs, A. M. (2009). Affective processing within 1/10th of a second: High arousal is necessary for early facilitative processing of negative but not positive words. Cognitive, Affective, \& Behavioral Neuroscience, 9, 389-397.

Hunt, R. R., \& Worthen, J. B. (2006). Distinctiveness and memory. New York, NY: Oxford University Press.

Jończyk, R. (2016). Affect-language interactions in native and non-native English speakers: A neuropragmatic perspective. Springer.

Kensinger, E. A. (2008). Age differences in memory for arousing and nonarousing emotional words. The Journals of Gerontology Series B: Psychological Sciences and Social Sciences, 63, 13-18.

Kensinger, E. A., \& Corkin, S. (2003). Memory enhancement for emotional words: Are emotional words more vividly remembered than neutral words? Memory \& Cognition, 31, 1169-1180.

Kissler, J., \& Herbert, C. (2013). Emotion, Etmnooi, or Emitoon?-Faster lexical access to emotional than to neutral words during reading. Biological Psychology, 92, 464-479.

Kousta, S. T., Vigliocco, G., Vinson, D. P., Andrews, M., \& Del Campo, E. (2011). The representation of abstract words: Why emotion matters. Journal of Experimental Psychology: General, 140, 14-34.

Kousta, S. T., Vinson, D. P., \& Vigliocco, G. (2009). Emotion words, regardless of polarity, have a processing advantage over neutral words. Cognition, 112, 473481. 
MacKay, D., Shafto, M., Taylor, J. K., Marian, D. E., Abrams, L., \& Dyer, J. R. (2004). Relations between emotion, memory, and attention: Evidence from taboo Stroop, lexical decision, and immediate memory tasks. Memory \& Cognition, 32, 474488.

Newcombe, P.I., Campbell, C., Siakaluk, P.D., \& Pexman, P.M. (2012). Effects of emotional and sensorimotor knowledge in semantic processing of concrete and abstract nouns. Frontiers in Human Neuroscience, 6, 275.

Opitz, B., \& Degner, J. (2012). Emotionality in a second language: it's a matter of time. Neuropsychologia, 50, 1961-1967.

Pavlenko, A. (2008). Emotion and emotion-laden words in the bilingual lexicon. Bilingualism: Language and Cognition, 11, 147-164.

Pavlenko, A. (2012). Affective processing in bilingual speakers: Disembodied cognition? International Journal of Psychology, 47, 405-428.

Ponari, M., Rodríguez-Cuadrado, S., Vinson, D., Fox, N., Costa, A., \& Vigliocco, G. (2015). Processing advantage for emotional words in bilingual speakers. Emotion, $15,644-652$.

Romani, C., McAlpine, S., \& Martin, R.C. (2008). Concreteness effects in different tasks: Implications for models of short-term memory. Quarterly Journal of Experimental Psychology, 61, 292-323.

Segalowitz, N., Trofimovich, P., Gatbonton, E., \& Sokolovskaya, A. (2008). Feeling affect in a second language: The role of word recognition automaticity. The Mental Lexicon, 3, 47-71.

Sheikh, N. A., \& Titone, D. (2016). The embodiment of emotional words in a second language: An eye-movement study. Cognition and Emotion, 30, 488-500. 
Warriner, A. B., Kuperman, V., \& Brysbaert, M. (2013). Norms of valence, arousal, and dominance for 13,915 English lemmas. Behavior research methods, 45, 11911207.

Williams, J. M. G., Mathews, A., \& MacLeod, C. (1996). The emotional Stroop task and psychopathology. Psychological Bulletin, 120, 3-24.

Winskel, H. (2013). The emotional Stroop task and emotionality rating of negative and neutral words in late Thai-English bilinguals. International Journal of Psychology, 48, 1090-1098.

Wu, Y. J., \& Thierry, G. (2012). How reading in a second language protects your heart. The Journal of Neuroscience, 32, 6485-6489.

Zhao, Y., \& Wang, Z. (2014). Concreteness of positive word contributions to affective priming: An ERP study. International Journal of Psychophysiology, 93, 275-282. 
Appendix. Critical stimuli used in the experiments (in alphabetical order of the Spanish words)

\section{Concrete}

Words

\section{Valence}

Spanish Word
Catalan Word

\section{Abstract}

Words
Translation

águila

amante

bailarín

bombero

campeona

canción

chico

chocolate

coito

condón

cumpleaños

dinero

erección

erótico

escenario

lotería

orgasmo

paracaídas

salario

àguila

amant

ballarí

bomber

campiona

cançó

noi

xocolata

coit

condó

aniversari

diners

erecció

eròtic

escenari

loteria

orgasme

paracaigudes

salari

eagle

lover

dancer

firefighter

champion (fem.) diversión

elogio

emoción

estimulación

éxito

fascinación

goce

hallazgo

heroísmo

incentivo

liberación

logro

maravilla

mérito

novedad

salary
Catalan Word

Translation

admired

$\operatorname{mood}$

attraction

wish

fun

compliment

emotion

stimulation

success

fascination

enjoyment

discovery

heroism

incentive

release

achievement

wonder

merit 


\begin{tabular}{|c|c|c|c|c|c|}
\hline simpático & simpàtic & sympathetic & pasión & passió & passion \\
\hline sorprendido & sorprès & surprised & seducción & seducció & seduction \\
\hline tobogán & tobogan & slide & sensualidad & sensualitat & sensuality \\
\hline trofeo & trofeu & trophy & superación & superació & improvement \\
\hline verbena & revetlla & festival & triunfador & triomfador & winner \\
\hline agresivo & agressiu & aggressive & abuso & abús & abuse \\
\hline ambulancia & ambulància & ambulance & altercado & altercat & dispute \\
\hline asesino & assassí & killer & angustia & angoixa & anguish \\
\hline asustado & espantat & scared & atrocidad & atrocitat & atrocity \\
\hline ataúd & taüt & coffin & calvario & calvari & torment \\
\hline atentado & atemptat & attack & cólera & còlera & anger \\
\hline atraco & atracament & robbery & conflicto & conflicte & conflict \\
\hline bofetada & bufetada & slap & crueldad & crueltat & cruelty \\
\hline bombardeo & bombardeig & bombing & desolación & desolació & desolation \\
\hline cadáver & cadàver & corpse & desorden & desordre & disorder \\
\hline celda & $\mathrm{cel} \cdot \mathrm{la}$ & cell & desprecio & menyspreu & contempt \\
\hline escorpión & escorpí & scorpion & egoísmo & egoisme & selfishness \\
\hline explosión & explosió & explosion & espanto & espant & horror \\
\hline fusil & fusell & rifle & espantoso & espantós & frightening \\
\hline herido & ferit & hurt & exclusión & exclusió & exclusion \\
\hline huracán & huracà & hurricane & fatalidad & fatalitat & fatality \\
\hline insomnio & insomni & insomnia & follón & merder & mess \\
\hline intruso & intrús & intruder & furia & fúria & fury \\
\hline inyección & injecció & injection & grave & greu & serious \\
\hline jeringa & xeringa & syringe & inseguridad & inseguretat & insecurity \\
\hline
\end{tabular}




\begin{tabular}{|c|c|c|c|c|c|}
\hline ladrón & lladre & thief & maldad & maldat & evil \\
\hline sangre & sang & blood & pánico & pànic & panic \\
\hline suicidio & suïcidi & suicide & quiebra & fallida & bankruptcy \\
\hline traidor & traïdor & traitor & rapto & rapte & kidnapping \\
\hline ayuntamiento & ajuntament & council & brevedad & brevetat & brevity \\
\hline balanza & balança & balance & código & codi & code \\
\hline bombilla & bombeta & lightbulb & combinación & combinació & combination \\
\hline capilla & capella & chapel & comentario & comentari & comment \\
\hline capitán & capità & captain & compasión & compassió & compassion \\
\hline cinturón & cinturó & belt & giro & gir & turn \\
\hline cuenco & bol & bowl & hábito & hàbit & habit \\
\hline esqueleto & esquelet & skeleton & herramienta & eina & tool \\
\hline garganta & gola & throat & institución & institució & institution \\
\hline ladrillo & maó & brick & manejo & maneig & use \\
\hline llovizna & plugim & drizzle & método & mètode & method \\
\hline maletero & maleter & trunk & molde & motlle & mold \\
\hline municipio & municipi & municipality & pausado & pausat & slow \\
\hline página & pàgina & page & rareza & raresa & rarity \\
\hline plástico & plàstic & plastic & rastro & rastre & trace \\
\hline plato & plat & plate & recado & encàrrec & errand \\
\hline portería & porteria & goal & regresión & regressió & regression \\
\hline pregón & pregó & proclamation & reservado & reservat & reserved \\
\hline propietario & propietari & owner & tamaño & mida & size \\
\hline provincia & província & province & tránsito & trànsit & traffic \\
\hline rubio & ros & blond & tregua & treva & truce \\
\hline
\end{tabular}




$\begin{array}{llllll}\text { rueda } & \text { roda } & \text { wheel } & \text { turno } & \text { torn } & \text { turn } \\ \text { ventanilla } & \text { finestreta } & \text { hatch } & \text { utensilio } & \text { utensili } & \text { gadget } \\ \text { vestíbulo } & \text { vestíbul } & \text { lobby } & \text { versión } & \text { versió } & \text { version }\end{array}$

